\title{
MULTI RESPONSE OPTIMIZATION OF MACHINING PARAMETERS FOR DRILLING OF ALUMINIUM 2219 ALLOY USING TAGUCHI AND GREY RELATION ANALYSIS
}

\section{LOKANATH M, SALEEMUDDIN S M, SURYA PRAKASH RVNR \& ESWAR BALACHANDAR G}

Assistant Professor, Department of Mechanical Engineering, AITS, Rajampet, AP-516126

\begin{abstract}
Aluminium alloys are highly resistant to corrosion. Aluminum 2219 composite is a compound containing age-hardening copper. Aluminum 2219 composite is a stronger in strength used in economic supercritical installations, such as spacecraft rockets and storage tanks. The aluminum alloy requires excellent mechanical properties due to excellent corrosion resistance. The alloy is flexible over a temperature with good rupture hardness.

This article perceives the optimal solution criteria that improve the rate of reduction of material and surface finish while drilling. Drill diameter, spindle speed and type of coolant are the control parameters chosen for the study. Using Gray relational Analysis, this multi-response optimization is accomplished for optimal conditions to which high MRR and lowest surface content were generated.

KEYWORDS: Drilling Parameters- MRR, Surface Roughness, Grey Relation Analysis and Aluminium Alloy
\end{abstract}

Received: Jun 06, 2020; Accepted: Jun 26, 2020; Published: Aug 21, 2020; Paper Id.: IJMPERDJUN2020845

\section{INTRODUCTION}

DRILLING can be defined as a process where a multi-point tool is used to remove materials, which are objectionable to the development of such a desired hole. It concerns mainly those methods used in the piece of work to construct cylindrical holes. Hole have historically have been described as the most prominent machining process, requiring specialized techniques to achieve the maximum cutting parameters. In an industry the drilling machines are commonly used in metal removal operations. Hence it is important to optimize output and profitability at about the same time.

The effects of the drilling parameters on the surface roughness and the error of roundness were examined in the drilling of the AI6061 alloy with HSS twist drills. Taguchi Grey's analyzes of the experimental outcomes recorded [1]. The effect of multiple process variables on material removal rate and surface roughness on Al-TiBr, Al6082, mild steel material on radial drilling is investigated using Grey relational analysis [2,3,8]. The effect on the drilling machine on glass fiber reinforced polymer as work surface of speed, point angle and feed on surface roughness and separation component [4]. solving the multi-response optimization problem in CNC end milling by taguchi method $[5,9,10]$. Taguchi methods are frequently used in the experiment layout and interpretation of test data for optimization production parameters. [6,7].

Aluminum combinations are profoundly impervious to consumption. Aluminum 2219 composite is a compound containing age-solidifying copper. Aluminum 2219 composite is a higher quality combination utilized in monetary supercritical establishments, for example, shuttle rockets and capacity tanks. The aluminum compound 
requires phenomenal mechanical properties because of superb consumption obstruction. The combination is adaptable over a temperature with great crack hardness.

\section{EXPERIMENTAL METHODS}

\section{Materials and Methods}

In this study, Al-2219 is used as the work piece material for drilling the hole on radial drilling process by using HSS drill bit, for measuring surface roughness Tool maker micro is used. The Specification of this work piece material are $75 \times 75 \times 12$ $\mathrm{mm}^{3}$. The chemical composition of the material, physical properties \& Mechanical properties are given in Table

Table

\begin{tabular}{|l|c|}
\hline Chemical Element & \% Present \\
\hline Aluminum & $91.5-93.8$ \\
\hline Copper & $5.8-6.8$ \\
\hline Iron & 0.3 \\
\hline Manganese & $0.2-0.4$ \\
\hline Silicon & 0.2 \\
\hline Titanium & $0.02-0.01$ \\
\hline Vanadium & $0.05-0.15$ \\
\hline Zinc & 0.1 \\
\hline Magnesium & 0.02 \\
\hline Zirconium & $0.10-0.25$ \\
\hline Residuals & 0.15 \\
\hline
\end{tabular}

General Properties of AL-2219

Table

\begin{tabular}{|c|c|}
\hline Physical Attributes & Value \\
\hline Density & $2.84 \mathrm{~g} / \mathrm{cm}^{3}$ \\
\hline Melting Point & $543-643^{\circ} \mathrm{C}$ \\
\hline Thermal Expansion & $23.5 \times 10^{\wedge}-6 / \mathrm{K}$ \\
\hline Modulus of Elasticity & $73.1 \mathrm{GPa}$ \\
\hline Thermal Conductivity & $120 \mathrm{~W} / \mathrm{m} . \mathrm{K}$ \\
\hline Tensile Strength & $414 \mathrm{Mpa}$ \\
\hline Proof stress & $290 \mathrm{Mpa}$ \\
\hline
\end{tabular}

\section{Grey Relational Analysis}

GRA uses a certain presumption of content. It summarizes conditions as black with no information, and white with perfect information. None of these individualistic outcomes, moreover, ever prevails in concerns of the real world. In particular, scenarios between contrasts, comprising Dispersed knowledge are represented as grey. A iteration of the GRA model, a GRA design based on Taguchi, is quite prominent in engineering. The process of GRA is shown in fig. The relational analysis emphasizes how to estimate and make the decisions, and generate reports that support vendor selection. This analytical model improves and confirms the Grey relationship among all parameters. 


\section{Methodology}

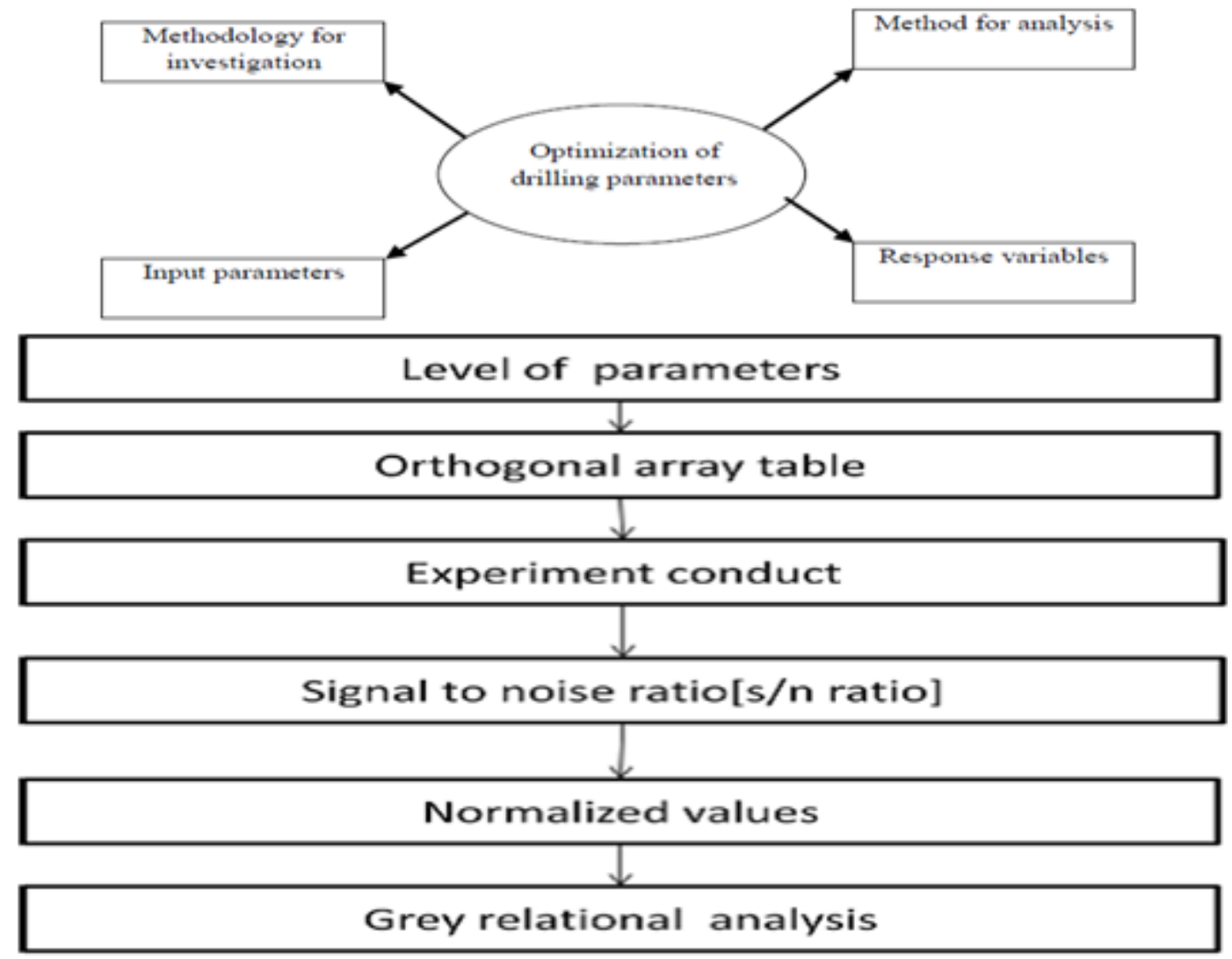

Figure 1: Approach used for Optimization Radial Drilling Process.

\section{Design of Experiment}

The investigational design for the machining parameters using the L27 orthogonal array of the drilling machine can be used for this study. The radial drilling machine was customized to the drilling process of Spindle speed of 830rpm, 1250rpm \& $18975 \mathrm{rpm}$, HSS tool with diameter of $9.5 \mathrm{~mm}, 10 \mathrm{~mm} \& 10.5 \mathrm{~mm}$ and the coolant like oil, kerosene, Water was used.

\section{Geometry of HSS Drill Bit}

Table 1: HSS Drill Bit

Tool Dia Flute Length Total Length|Point Angle Helix Angle

\begin{tabular}{|c|c|c|c|c|}
\hline $\mathbf{( m m})$ & $(\mathbf{m m})$ & $(\mathbf{m m})$ & (degrees) & (degrees) \\
\hline 9.5 & 115 & 175 & 118 & 30 \\
\hline 10 & 121 & 184 & 118 & 30 \\
\hline 10.5 & 128 & 195 & 118 & 30 \\
\hline
\end{tabular}

Table 2: Process Parameters and their Levels

\begin{tabular}{|l|c|c|c|}
\hline \multicolumn{1}{|c|}{ Input } & Level 1 & Level 2 & Level 3 \\
\hline Speed (rpm) & 830 & 1250 & 1895 \\
\hline Tool diameter(mm) & 9.5 & 10 & 10.5 \\
\hline Type of coolant & Water & Kerosene & Oil \\
\hline
\end{tabular}

In any drilling machining operation, surface roughness (SR) and material removal rate (MRR) are two essential parts of a material. The array having a three control parameter and three levels are shown in table 1. This process, all 
identified quantities are determined more essential based on the maximum the better and the minimum the better. In the present study spindle speed, Coolant and drill bit have been selected as design factor the other parameter have been assumed to be constant. This experiment focused on the maximum, intermediate and minimum values observed of MRR and SR together. Every experimental study in each set value was implemented with three easy analyses. Next, by comparing the standard analysis and the grey relational analysis, the optimization of the measured parameters was estimated.
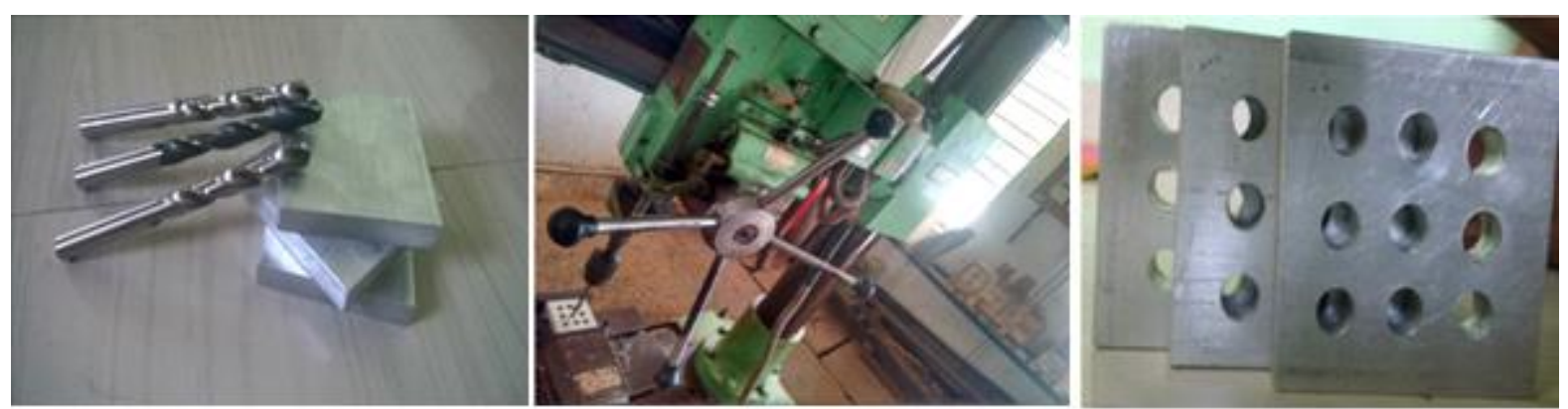

Figure 2: Shows Aluminium 2219 ALLOY, Radial Drilling Machine and Work Pieces After Drilling.

\section{Drilling Experimental Values}

By doing the experiment the cutting speed is measured as per the L27

Table 3: Design of Experiments

\begin{tabular}{|c|c|c|l|}
\hline S.NO & Spindle Speed in rpm & Tool Diameter in mm & Cutting Environment \\
\hline 1 & 830 & 9.5 & Water \\
\hline 2 & 830 & 9.5 & Kerosene \\
\hline 3 & 830 & 9.5 & Oil \\
\hline 4 & 830 & 10 & Water \\
\hline 5 & 830 & 10 & Kerosene \\
\hline 6 & 830 & 10 & Oil \\
\hline 7 & 830 & 10.5 & Water \\
\hline 8 & 830 & 10.5 & Kerosene \\
\hline 9 & 830 & 10.5 & Oil \\
\hline 10 & 1250 & 9.5 & Water \\
\hline 11 & 1250 & 9.5 & Kerosene \\
\hline 12 & 1250 & 9.5 & Oil \\
\hline 13 & 1250 & 10 & Water \\
\hline 14 & 1250 & 10 & Kerosene \\
\hline 15 & 1250 & 10 & Oil \\
\hline 16 & 1250 & 10.5 & Water \\
\hline 17 & 1250 & 10.5 & Kerosene \\
\hline 18 & 1250 & 10.5 & Oil \\
\hline 19 & 1895 & 9.5 & Water \\
\hline 20 & 1895 & 9.5 & Kerosene \\
\hline 21 & 1895 & 9.5 & Oil \\
\hline 22 & 1895 & 10 & Water \\
\hline 23 & 1895 & 10 & Kerosene \\
\hline 24 & 1895 & 10 & Oil \\
\hline 25 & 1895 & 10.5 & Water \\
\hline 26 & 1895 & 10.5 & Kerosene \\
\hline 27 & 1895 & 10.5 & Oil \\
\hline & & & \\
\hline
\end{tabular}


Table 4: Experimental Results

\begin{tabular}{|c|c|c|l|c|c|}
\hline S.NO & Spindle Speed in rpm & Tool Diameter in $\mathbf{~ m m}$ & Coolant type & MRR $\left(\mathbf{m m}^{\mathbf{3}} / \mathbf{m i n}\right)$ & Ra $(\boldsymbol{\mu m})$ \\
\hline 1 & 830 & 9.5 & Water & 179.48 & 2.357 \\
\hline 2 & 830 & 9.5 & Kerosene & 191.38 & 2.177 \\
\hline 3 & 830 & 9.5 & Oil & 179.48 & 2.56 \\
\hline 4 & 830 & 10 & Water & 161.79 & 3.183 \\
\hline 5 & 830 & 10 & Kerosene & 199.49 & 2.858 \\
\hline 6 & 830 & 10 & Oil & 193.99 & 2.678 \\
\hline 7 & 830 & 10.5 & Water & 312.59 & 2.691 \\
\hline 8 & 830 & 10.5 & Kerosene & 206.95 & 2.884 \\
\hline 9 & 830 & 10.5 & Oil & 220.8 & 2.979 \\
\hline 10 & 1250 & 9.5 & Water & 177.25 & 6.521 \\
\hline 11 & 1250 & 9.5 & Kerosene & 194.21 & 4.665 \\
\hline 12 & 1250 & 9.5 & Oil & 185.002 & 2.781 \\
\hline 13 & 1250 & 10 & Water & 237.97 & 3.169 \\
\hline 14 & 1250 & 10 & Kerosene & 215.19 & 3.889 \\
\hline 15 & 1250 & 10 & Oil & 188.49 & 8.074 \\
\hline 16 & 1250 & 10.5 & Water & 249.37 & 3.128 \\
\hline 17 & 1250 & 10.5 & Kerosene & 237.25 & 3.18 \\
\hline 18 & 1250 & 10.5 & Oil & 216.47 & 6.617 \\
\hline 19 & 1895 & 9.5 & Water & 179.33 & 5.798 \\
\hline 20 & 1895 & 9.5 & Kerosene & 192.09 & 2.879 \\
\hline 21 & 1895 & 9.5 & Oil & 179.33 & 8.89 \\
\hline 22 & 1895 & 10 & Water & 186.13 & 3.224 \\
\hline 23 & 1895 & 10 & Kerosene & 198.73 & 6.274 \\
\hline 24 & 1895 & 10 & Oil & 198.73 & 8.295 \\
\hline 25 & 1895 & 10.5 & Water & 219.07 & 3.796 \\
\hline 26 & 1895 & 10.5 & Kerosene & 191.36 & 4.229 \\
\hline 27 & 1895 & 10.5 & Oil & 219.07 & 3.834 \\
\hline
\end{tabular}

\section{RESULT AND DISCUSSION}

\section{Taguchi’s Signal-to-Noise Ratio Analysis on Responses Variables}

Scientific analysis of the experimental results obtained via Taguchi experimental design was conducted out using quantitative software MINITAB 16 as shown in table5.7. In this step, S / N ratios are measured for drilling action response and the optimum configuration of input parameters is calculated based on the quality requirement. Surface roughness will be low for better quality while drilling the response characteristics, hence smaller $\mathrm{S} / \mathrm{N}$ ratios for these parameters are regarded. Whereas for machining the material removal is higher, consideration given to larger $\mathrm{S} / \mathrm{N}$ ratios.

Signal-To-Noise Ratio for the Smaller-The-Better: Surface Roughness

$\mathbf{S} / \mathrm{N}=-10 * \log ($ mean square of the response)

$$
S / N=-10 \log _{10}\left(\frac{1}{n} \sum y 2\right)
$$




\section{Larger-The-Better: MRR}

$\mathrm{S} / \mathrm{N}=-10 * \log$ (mean square of the inverse of the response)

$$
S / N=-10 \log _{10}\left(\frac{1}{n} \sum \frac{1}{y^{2}}\right)
$$

Table 5: S/N Ratio for Response Variables

\begin{tabular}{|c|c|c|}
\hline S.NO & MRR & $\mathbf{R a}$ \\
\hline 1 & 45.0803 & -7.4472 \\
\hline 2 & 45.6379 & -6.7572 \\
\hline 3 & 45.0803 & -8.1648 \\
\hline 4 & 44.1790 & -10.0567 \\
\hline 5 & 45.9984 & -9.1212 \\
\hline 6 & 45.7556 & -8.5562 \\
\hline 7 & 49.8995 & -8.5983 \\
\hline 8 & 46.3173 & -9.1999 \\
\hline 9 & 46.8800 & -9.4814 \\
\hline 10 & 44.9717 & -16.2863 \\
\hline 11 & 45.7654 & -13.3770 \\
\hline 12 & 45.3435 & -8.8840 \\
\hline 13 & 47.5304 & -10.0184 \\
\hline 14 & 46.6564 & -11.7968 \\
\hline 15 & 45.5058 & -18.1418 \\
\hline 16 & 47.9369 & -9.9053 \\
\hline 17 & 47.5041 & -10.0485 \\
\hline 18 & 46.7080 & -16.4132 \\
\hline 19 & 45.0731 & -15.2656 \\
\hline 20 & 45.6701 & -15.0533 \\
\hline 21 & 45.0731 & -18.9780 \\
\hline 22 & 45.3963 & -10.1679 \\
\hline 23 & 45.9653 & -15.9509 \\
\hline 24 & 45.9653 & -18.3763 \\
\hline 25 & 46.8117 & -11.5865 \\
\hline 26 & 45.6370 & -12.5248 \\
\hline 27 & 46.8117 & -11.6730 \\
\hline
\end{tabular}

\section{Grey Relation Analysis}

\section{Normalization of S/N Ratio Values}

For S / N ratio normalization, higher is better for MRR (a) lower is better for surface Roughness (b)

$$
x_{i}^{*}=\frac{x_{i}^{o}(\mathrm{k})-\min x_{i}^{o}(\mathrm{k})}{\max x_{i}^{o}(\mathrm{k})-\min x_{i}^{o}(\mathrm{k})} \quad x_{i}^{*}=\frac{\max x_{i}^{o}(\mathrm{k})-x_{i}^{o}(\mathrm{k})}{{\max x_{i}^{o}(\mathrm{k})-\min x_{i}^{o}(\mathrm{k})}^{\operatorname{man}}}
$$

\section{Calculation of Grey Relational Coefficient (GRC)}

GRC demonstrates the relation between the best and the actual normalized $\mathrm{S} / \mathrm{N}$ ratio for all sequences. If the two sequence align at all stages, then their coefficient of Grey relation is 1 . The grey relational coefficient $\xi_{i}(\mathrm{k})$ for the $k t_{\mathrm{h}}$ performance characteristics in the $i_{\text {th }}$ experiment can be expressed as : 


$$
\xi i(k)=\frac{\Delta_{\min }+\zeta \Delta_{\max }}{\Delta_{o i}(k)+\zeta \Delta_{\max }}
$$

$\Delta o_{i \mathrm{i}}$ is the deviation sequence and the comparability sequence $\zeta$ is identification coefficient $\zeta$ range from 0 to 1.

The smaller is a value of prevalence and the larger is the prominent ability. Typically, $\zeta=0.5$ is used for grey relational coefficient for 27 sequences of comparability as shown in table.

\section{Calculation of Grey Relational Grade (GRG)}

It is acceptable to take the estimated value of the grey relational coefficients as the grey relational grade, after the grey relational coefficient is obtained. The grey relational grade is defined as follows:

$$
\gamma_{\mathrm{i}=1 / \mathrm{n}} \sum_{k=1}^{n} \xi i(k)
$$

The grey relational grade $\gamma i$ reflects the degree of similarity between the sequence of reference and the sequence of comparability.

\begin{tabular}{|c|c|c|c|c|c|c|}
\hline S.NO & $\begin{array}{l}\text { Normalization of } \mathrm{S} / \mathrm{N} \\
\text { ratio values MRR }\end{array}$ & $\mathbf{R a}$ & $\begin{array}{l}\text { Grey Relational } \\
\text { coefficient MRR }\end{array}$ & $\mathbf{R a}$ & $\begin{array}{c}\text { Weighted Grey } \\
\text { Relational grade }\end{array}$ & Rank \\
\hline 1 & 0.1576 & 0.0565 & 0.3725 & 0.3464 & 0.3594 & 27 \\
\hline 2 & 0.255 & 0 & 0.4016 & 0.3333 & 0.3675 & 25 \\
\hline 3 & 0.1576 & 0.1152 & 0.3725 & 0.3611 & 0.3668 & 26 \\
\hline 4 & 0 & 0.27 & 0.3333 & 0.4065 & 0.3699 & 24 \\
\hline 5 & 0.318 & 0.1934 & 0.423 & 0.3827 & 0.4029 & 20 \\
\hline 6 & 0.2756 & 0.1472 & 0.4084 & 0.3696 & 0.389 & 22 \\
\hline 7 & 1 & 0.1507 & 1 & 0.3705 & 0.6864 & 1 \\
\hline 8 & 0.3738 & 0.1999 & 0.444 & 0.3846 & 0.4143 & 19 \\
\hline 9 & 0.4722 & 0.2229 & 0.4865 & 0.3915 & 0.439 & 18 \\
\hline 10 & 0.1386 & 0.7797 & 0.3673 & 0.6942 & 0.5307 & 7 \\
\hline 11 & 0.2773 & 0.5417 & 0.4089 & 0.5218 & 0.4653 & 15 \\
\hline 12 & 0.2036 & 0.174 & 0.3857 & 0.3771 & 0.3814 & 23 \\
\hline 13 & 0.5859 & 0.2669 & 0.547 & 0.4055 & 0.4762 & 11 \\
\hline 14 & 0.4331 & 0.4124 & 0.4686 & 0.4597 & 0.4642 & 16 \\
\hline 15 & 0.2319 & 0.9316 & 0.3943 & 0.8796 & 0.637 & 4 \\
\hline 16 & 0.6569 & 0.2576 & 0.5931 & 0.4024 & 0.4978 & 9 \\
\hline 17 & 0.5813 & 0.2693 & 0.5442 & 0.4063 & 0.4753 & 12 \\
\hline 18 & 0.4421 & 0.7901 & 0.4726 & 0.7044 & 0.5885 & 5 \\
\hline 19 & 0.1563 & 0.6962 & 0.3721 & 0.6221 & 0.4971 & 10 \\
\hline 20 & 0.2607 & 0.6788 & 0.4034 & 0.6089 & 0.5062 & 8 \\
\hline 21 & 0.1563 & 1 & 0.3721 & 1 & 0.6853 & 2 \\
\hline 22 & 0.2128 & 0.2791 & 0.3884 & 0.4095 & 0.399 & 21 \\
\hline 23 & 0.3123 & 0.7523 & 0.421 & 0.6687 & 0.5448 & 6 \\
\hline 24 & 0.3123 & 0.9508 & 0.421 & 0.9104 & 0.6657 & 3 \\
\hline 25 & 0.4602 & 0.3952 & 0.4809 & 0.4526 & 0.4667 & 14 \\
\hline 26 & 0.2549 & 0.4719 & 0.4016 & 0.4864 & 0.444 & 17 \\
\hline 27 & 0.4602 & 0.4023 & 0.4809 & 0.4555 & 0.4682 & 13 \\
\hline
\end{tabular}

Table 6: Grey Relational Grade

It is clearly observed from above in Table 6 according to the design of the experiment conducted. That specification of the drilling parameters for experiment No. 7 has the highest level of grey relation. Experiment No. 7 is, therefore, the optimized setting of the machining constraints for minimum surface roughness and maximum material 
removal rate among the 27 experiments. In contrast to evaluating the optimum drilling parameters for surface roughness and MRR, the Taguchi method approach table was used to estimate the mean grey relational grade for each level of the drilling variables. The process is: I group the grey relational grades in the orthogonal array by factor level between each column, ii) take the average of them.

The grey relational grade for factor $\mathrm{A}$ at level 1 for example can be determined as $\gamma \mathrm{A} 1=(0.3594+0.3675+0.3668+0.3699+0.4029+0.3890++0.6864+0.4143+0.4390)=0.4216$.

For each stage of the drilling parameters the grey relational grade values were determined using the same approach is shown in Table 6. A higher grey relational grade value corresponds to better quality regardless of the performance characteristics level. Therefore, the optimal level of the machining parameters is the level based on the grey relational grade valve given in Table 6.5, the optimal machining performance for both the surface roughness and the MRR is determined at $1895 \mathrm{rpm}$ spindle speed (level 3), $10.5 \mathrm{~mm}$ Toll diameter (level 3) and oil as coolant (level 3) combination. The optimal drilling parameter levels can be shortly given as A3, B3 and C3.

Table 7: The Response Table for Grey Relational Grade

\begin{tabular}{|l|c|c|c|c|}
\hline & Level 1 & Level 2 & Level 3 & Max-Min \\
\hline Spindle Speed(A) & 0.4216 & 0.5018 & 0.5196 & 0.098 \\
\hline Toll Diameter(B) & 0.4612 & 0.4831 & 0.5031 & 0.041 \\
\hline Cutting Environment(C) & 0.4759 & 0.4538 & 0.5130 & 0.0592 \\
\hline
\end{tabular}

The difference between the maximum and minimum value of the grey relation grade of the drilling parameters as described in Table 7 is as adopts: 0.098 for spindle speed, 0.041 for tool diameter and 0.0592 for cutting environment. This comparison will give the level of significance of the controllable factors over the multi performance characteristics. The average of these values among $0.098,0.041$ and 0.0592 is 0.098 , was the most effective controllable factor. The value shows that the speed of the spindle has the strongest effect on the multi-performance characteristics associated with other parameters of the drilling. The order of importance of the controllable factors in the drilling process for the multiperformance characteristics, in sequence order as factor A (spindle speed), B (Toll diameter) and C (type of coolant) (i.e0.098>0.0592>0.041) among attributes spindle speed for the drilling was strongly affected.

\section{CONCLUSIONS}

Subsequent ends can be drawn from the impact of penetrating machining parameters on reaction factors including material expulsion rate (MRR) and surface completion, on AL-2219 materials. The ideal setting which decides the most elevated conceivable MRR and the least harshness of the surface is A3-B3-C3. The shaft speed is $830 \mathrm{rpm}$, the distance across of a device is $10.5 \mathrm{~mm}$ and the water is coolant. The most noteworthy dark social evaluation of 0.6864 was watched for test run 7 as appeared in the perception of the normal dim social evaluation, showing an ideal mix of control factors. The surface completion standard compels the MRR while choosing the ideal mix of MRR and surface completion. Based on the normal GRG acquired in the current work, the impact of the GRG of procedure parameters are positioned as Spindle speed-I, drill width - II and coolant stream III.

\section{REFERENCES}

1. Reddy Sreenivasulu and Dr. Ch. SrinivasaRao, "Application of Grey Relational Analysis for Surface Roughness and Roundness Error in Drilling of Al 6061 Alloy", International Journal of Lean Thinking Volume 3, Issue 2, pp. 67-78, December 2012. 
2. B. Shivapragash, K. Chandrasekaran, C. Parthasarathy and M. Samuel, "Multi Response Optimizations in Drilling Using Taguchi and Grey Relational Analysis”, International Journal of Modern Engineering Research, Vol.3, Issue.2, pp-765-768, March-April. 2013.

3. Devireddy, Krishnaja., et al. "Analysis of the influence of friction stir processing on gas tungsten arc welding of 2024 aluminum alloy weld zone." Int. J. Mech. Prod. Eng. Res. Dev 8.1 (2018): 243-252.

4. Nisha tamta and RS jadoun, "A Review on Optimization of Cutting Parameters in Drilling using Taguchi Method", International Journal of Engineering Trends and Technology (IJETT), V29(2),82-86 November 2015. ISSN:2231-5381 Merchant, M. E., "Recent progress in metal removal research at Cincinnati”, Int. J.M.T.D.R.

5. Abolusoro, Olatunji P., and Esther T. Akinlabi. "Wear and corrosion behaviour of friction stir welded aluminium alloys-an overview." Int J Mech Prod Eng Res Dev 9 (2019): 967-82.

6. Shunmugesh K, Panneerselvam. K and Jospaul Thomas, "Optimising Drilling Parameters Of GFRP By Using Grey Relational Analysis", International Journal of Research in Engineering and Technology, Volume: 03 Issue: 06, pp. 302- 305, Jun-2014.

7. K. Taraman, Multi machining output-multi independent variable turning research by responsesurface methodology, International Journal of ProductionResearch 12 (1974) 233-245.

8. Chu, NGOC-HUNG, and V. D. Nguyen. "The Multi-Response Optimization of Machining Parameters in the Ultrasonic Assisted Deep-Hole Drilling Using Grey-Based Taguchi Method." Int. J. Mech. Prod. Eng. Res. Dev 8 (2018): 417-426.

9. K. Lipin and p.govindan ,"A Review on Multi Objective Optimization of Drilling Parameters Using Taguchi Methods", AKGEC International Journal of Technology, Vol. 4, No. 2,june2010

10. J. Siva Subramanian et al, "Study on Drilling Process Parameters - Review", International Journal of Engineering Research \& Technology (IJERT), ISSN: 2278-0181 ICONNECT - 2k18 Conference Proceedings

11. D. Kumar, L.P. Singh and G. Singh, , Operational Modeling For Optimizing Surface roughness in Mild Steel Drilling Using Taguchi Technique, International Journal of Research in Management, Vol. 2, No. 3, 2012, pp. 66-77.

12. Joshi, Jyoshna, and Onkar Sonare. "Optimisation of Wire EDM Process Parameters on D3 Tool Steel using Principal Component Analysis." International Journal of Mechanical and Production Engineering Research and Development (IJMPERD) 7.2 (2013): 31-40.

13. B. Shivapragash, K. Chandrasekharan, C. Parthasarathy and M. Samuel, Multiple Response Optimizations in Drilling Using Taguchi and Grey Relational Analysis, International Journal of Modern Engineering Research, Vol. 3, No. 2, 2013, pp.765768.

14. K.P. Patel, Experimental Analysis On Surface Roughness Of CNC End Milling Process Using Taguchi Design Method, International Journal of Engineering Science and Technology, Vol. 4, No. 2, 2012, pp.540-545 

